\title{
Eksenel Basınç Yükü Altında Farklı Ebatlı Beton Küp Numunelerde Boyut Etkisinin İncelenmesi
}

\author{
Hakan Aydın ${ }^{1 *}$ \\ 1*illkadım Belediyesi, Ar\&Ge Müdürlüğü, Samsun, Türkiye, (ORCID: 0000-0002-1886-5497), hakanaydin@ilkadim.bel.tr
}

(1st International Conference on Applied Engineering and Natural Sciences ICAENS 2021, November 1-3, 2021)

(DOI: 10.31590/ejosat.1015776)

\begin{abstract}
ATIF/REFERENCE: Aydın, H. (2021). Eksenel Basınç Yükü Altında Farklı Ebatlı Beton Küp Numunelerde Boyut Etkisinin İncelenmesi. Avrupa Bilim ve Teknoloji Dergisi, (28), 1388-1398.
\end{abstract}

Öz

Aynı geometriye sahip beton numuneler üzerinde yapılan bu deneysel araştırmada numune boyutu ile nominal basınç dayanımı arasında numune boyutunun artması ile nominal dayanımın azaldığı sonucuna ulaşılmıştır. Bu olay beton ve betonarmenin kırılma mekaniğinde boyut etkisi olarak adlandırılmaktadır. Eksenel basınç yükü altında Laboratuvar koşullarında üretilen değişik basınç dayanımlarındaki küp beton numunelerde kırılma yükleri deneysel olarak elde edilmiştir. Ulaşılan sonuçlarla boyut etkisi eğrileri çizilip, ilgili boyut etkisi parametreleri hesaplanmıştır. Farklı beton sinıflarında (C20, C25, C30, C35, C40) beş ayrı grupta küp numunelerle toplam 45 adet beton deney numunesi kullanılmıştır. Çalışmada her bir beton sınıfı alfabetik olarak sırasıyla (A, B, C, D, E) olarak harflendirilmiştir. Çalışmada ulaşılan sonuçlara Bazant'ın boyut etkisi metodunun Lineer I, Lineer II ve Non-lineer ile Carpinteri'nin MFSL (Multifractal Scaling Law) analizleri uygulanmış ve boyut etkisi bağıntıları elde edilmiştir. Deneysel verilerden elde edilen sonuçlar ilgili boyut etkisi denklemlerine çok iyi uymuştur. Beton dayanımınlarının boyut etkisi teorisi ile korelasyonu tam olarak kurulmuştur. Boyut etkisinin varlığı, farklı dayanımlara sahip küp numunelerle yapılan deneylerden elde edilen sonuçlarla açıkça görülmüştür.

Anahtar Kelimeler: Kırılma mekaniği, boyut etkisi, basınç dayanımı, beton deneyleri, küp numune

\section{Investigation of Size Effect on Concrete Cube Samples of Different Sizes Under Axial Compressive Load}

\begin{abstract}
In this experimental study conducted on concrete samples with the same geometry, it was concluded that the nominal strength decreases with increasing sample size between sample size and nominal compressive strength. This phenomenon is called the size effect in the fracture mechanics of concrete and reinforced concrete. Fracture loads were obtained experimentally for cube concrete specimens with different compressive strengths produced under laboratory conditions under axial compressive load. With the results obtained, size effect curves were drawn and related size effect parameters were calculated. A total of 45 concrete test samples were used with cube samples in five different groups in different concrete classes (C20, C25, C30, C35, C40). In the study, each concrete class is alphabetically lettered as (A, B, C, D, E). Linear I, Linear II and Non-linear analyzes of Bazant's size effect method and MFSL (Multifractal Scaling Law) analysis of Carpinteri were applied to the results obtained in the study, and size effect curves and parameters were obtained. The existence of the size effect was clearly seen with the results obtained from the experiments performed with cube samples with different strengths.
\end{abstract}

Keywords: Fracture mechanics, size effect, compressive strength, reinforced concrete experiments, cube specimen

\footnotetext{
* Sorumlu Yazar: hakanaydin@,ilkadim.bel.tr
} 


\section{Giriş}

Mühendislik yapıların tasarım aşamasında dikkate alınanlar yeterli dayanım, yeterli rijitlik ve yeterli süneklik olmaktadır. Yapılar diş yüklerle birlikte rötre, sünme, dinamik yükler ve mesnet çökmesi gibi yük etkilerinin etkisi altında olduğunda, bu durumda yapısal davranışın belirlenmesinde en önemli parametreler arasında sayılmaktadırlar. (Doğangün, 2002; Tuhta vd.2019; Koç ve Tuhta, 2012, Tuhta vd.2020).

Yük maksimum değerine ulaştıktan sonra artan deformasyonlarda yükün neredeyse sabit kaldığı göçmeler sünektir. Gevrek davranışa sahip malzemelerde ise maksimum değere ulaştıktan sonra yük hızla azalır. Plastik davranışta, geometrik olarak aynı boyutlara sahip elemanlar yaklaşık olarak aynı gerilme seviyesinde çökerken, gevrek davranışta, boyutlar arttıkça göçmedeki nominal gerilme önemli ölçüde azalır. (Koç ve Şener,2003; Bazant vd.,1998; Aydın ,2010; Akkaya vd.,2003).

Mevcut yönetmelik TS 500, plastik limit analizine dayanmaktadır ve boyut etkisi göstermemektedir. Başka bir deyişle, farklı boyutlardaki geometrik olarak benzer elemanlar aynı gerilmede göçerler. Plastik limit analizinde yapı, kırılma anında tek serbestlik dereceli sistem gibi davranır ve kırılma yüzeyindeki tüm noktalar aynı anda hareket eder ve göçer. Gerçekte, malzeme mukavemeti, kırılma yüzeyinin farklı noktalarında farklı zamanlarda aşılır. (Koç,2007, Aydın,2010).

Basınç dayanımı, beton ve beton esaslı yapıların tasarımında kullanılan betonun en önemli mühendislik özelliklerinden biridir. Bununla birlikte, önceki testler ve teorik araştırmalar, laboratuvarda test edilen betonun mukavemetinin numunenin şekli ve boyutundan güçlü bir şekilde etkilendiğini ve sonuç olarak, betonun ölçülen mukavemeti, doğal bir malzeme özelliği değil, malzeme ve yapısal davranışın bir kombinasyonudur.

Beton basınç dayanımının boyut etkisi olgusu ilk olarak (Gonnerman,1925) tarafından deneysel olarak gösterilmiş ve daha sonra (Weibull,1939)'un teorisi ile açıklanmıştır. 1980'lerden bu yana, betonun kırılma mekaniği kavramına dayalı olarak, beton dayanımının boyut etkisi için bir dizi teorik model geliştirilmiştir. (Bazant vd.,1998) ve (Kim ,1990) sırasıyla, boyut etkisi yasasını (SEL) ve değiştirilmiş boyut etkisi yasasını (MFSEL) türetmiştir. (Carpinteri vd. (1994), çok fraktal ölçekleme yasasını (MFSL) türetmiştir. Bu boyut etkisi modelleri, betonun boyut etkisini bir dereceye kadar açıklayabilir. Öte yandan, bazı araştırmacılar numune boyutunun artmasıyla beton dayanımının azalmasını açıklamak için ampirik ifadeler geliştirmiştir (Akkaya vd., 2003; Koç., 2007; Che Y., vd.2010).

Kırılma mekaniği, göçmenin yapıdaki ilerlemesini dikkate alan, mukavemetsel enerji kriterlerini kullanan bir göçme teorisidir. Mikro çatlaklar hemen her yapı içinde vardır ve göçme, gerilmeler yükleri altında çatlakların birbirleriyle birleşmesinden oluşmaktadır. (Bazant vd.,1998; Koç,2007; Akkaya vd., 2003).

(Hillerborg, 1983) Kırılmanın türü basınç olsa bile, temelde kırılma süreci her zaman çekme mukavemeti aşıldığında meydana gelir. Betonarme gibi elemanların tasarımında boyut etkisinin kullanılması önemli faydalar sağlamaktadır. Özellikle boyut etkisi dikkate alınarak farklı ebatlardaki yapı elemanları için aynı güvenliği sağlamak mümkündür. Böylece daha güvenli, daha ekonomik bina tasarımı ve yeni beton malzeme ve yeni tasarım yöntemleri kullanma olasılığı artar. Boyut etkisinin kullanılması ile yüksek dayanımlı betonlar, çok büyük boyutlu yapılar (barajlar, nükleer santraller, savunma yapıları gibi) ve öngerilmeli yapılar daha güvenli ve ekonomik olarak inşa edilebilir. (ACI Report,1992; Shah vd.,1995; Van ve J.G.M,1997; Erdoğan, 2000, Akkaya vd.2003). Beton yarı kırılgan bir malzemedir, kırılma bölgesinin oluşumu ve gelişimi, cam, metal vb malzemelerden çok farklıdır.

Yurtiçinde ve yurtdışında birçok araştırmacı betonun boyut etkisi üzerine birçok araştırma yapmış ve başarılı sonuçlar elde etmişlerdir. Beton dayanımının boyut etkisi üzerine hem deneysel hem de teorik olarak kapsamlı çalışmalar yapılmıştır. (Koç ve Şener,2003, Koç,2007, Şanal, 2018, Koç ve Birinci, 2012). Beton küp numuneler üzerinde boyut etkisini içeren çalışmalardan (Neville,1956) üç boyutlu beton küp numuneler $(70,125,150 \mathrm{~mm})$ üzerinde basınç deneyleri yapmış ve sonucunda küçük numunelerin büyük numunelerden daha yüksek dayanıma sahip olduğu sonucuna ulaşmıştır.

(Şanal,2018) yapmış olduğu deneysel çalışmasında beton deneylerinde kullanılan numunelerinin boyut ve ebatlarının deneysel sonuçlara etkilerini kapsamlı olarak değerlendirmiş ve 100mm'lik küplerin pratikte kullanımının uygun olduğu sonucuna ulaşmıştır.

(Koç ve Birinci, 2013) Normal ve lifli betondan hazırlanan boyutları büyük numuneden küçük numuneye doğru 4:2:1 benzerlik oranlarına sahip konsol elemanlardan konsol eksenlerine paralel basınç yüklemesi uygulayarak yaptıkları analizlerler sonucunda boyut boyut etkisi parametrelerini bulmuşlar, logaritmik eksen takımlı boyut etkisi eğrilerini düzenlemişlerdir. (Sabnis,1979), 12 araştırmacı tarafından farklı beton koşulları, farklı kür yöntemleri ve farklı yaşlar altında elde edilen deneysel verileri analiz etmişler ve boyut etkisi dikkate alınarak beton basınç dayanımının ampirik denklemini elde etmişlerdir. Beton malzemenin boyut etkisinin bir çok faktörden etkilendiği sonucuna ulaşmışlardır.

Yang ve Wu., (1997), tam dereceli ve 1slak beton küp numuneleri üzerinde tek eksenli basınç dayanımı testleri gerçekleştirmişler ve çalışmanın sonucunda hem tam dereceli hem de rslak betonun mukavemetinin boyut etkisine sahip olduğunu ve değişim yasasının Weibull istatistiksel teorisi ile tutarlı olduğunu göstermişlerdir.

Chen Wei vd., (2014), tek eksenli yükleme altında 3 farklı beton küp numuneler üzerinde farklı dinamik yükleme hızlarında (10- 5,10-4,10-3,10-2/s) yaptıkları beton basınç dayanım testlerinde farklı numune boyutlarının beton tepe gerilmeleri ile olan varyasyon analizlerini yapmışlardır. Weibull ve Bazant boyut etkisi modellerine gerinim hızının etkisini dahil ederek, deformasyon hızı etkisi dikkate alınarak beton dayanımının boyut etkisi modelini oluşturmuşlardır.

$\mathrm{Bu}$ çalışma ile amaçlanan literatürdeki araştırmalarla ilgili çalışmalara katkı sağlayacak düzeyde numune boyutunun ve geometrinin betonun basınç dayanımı üzerindeki etkisini araştırmaktır. Eksenel basınç yükü altında Laboratuvar koşullarında üretilen değişik basınç dayanımlarındaki $200 \mathrm{~mm}$, $100 \mathrm{~mm}$ ve $50 \mathrm{~mm}$ arasında değişen beton küp numuneler hazırlanmış ve test edilmiştir. Kırılma yükleri deneysel olarak elde edilerek ulaşılan sonuçlarla boyut etkisi eğrileri çizilip, ilgili boyut etkisi parametreleri hesaplanacaktır. 


\section{Materyal ve Metot}

\subsection{Hazırlanan Deney Numuneleri ve Özellikleri}

5 farklı dayanımda beton sınıfı kullanılarak hazırlanan bu çalışmada Hazır Beton Santralinde üretilen seri betonlar kullanılmıştır. Her bir seri farklı ebatlarda küp numunelerden oluşmaktadır. Deney grubunda boyutları birbirinin 1:2:4 katı olan deney numuneleri hazırlanmış ve kullanılmıştır. Bir deney grubu içinde 3 adet büyük, 3 adet orta ve 3 adet küçük deney numuneleri nden toplamda 9 adet ve 5 farklı dayanımda toplam 45 adet deney numunesi hazırlanmıştır. Küçük beton küp deney numune ebatları $50 \times 50 \times 50 \mathrm{~mm}$, orta boy beton küp deney numune ebatlar1 100x100x100 mm, büyük beton küp deney numune boyutlar1 200x200x200 mm'dir (Şekil 1.1). Deney numunelerini isimlendirmede küp (Cupe) numuneler için CU harfleri kullanılmıştır. Üçüncü harf deney gruplarını göstermekte olup her bir seri için A, B, C, D, E harfleri kullanılmıștır. Beton küp numune kalıplarının hazırlanmasıda çelik saç malzeme kullanılmıştır (Şekil 1.2). Bu çalışmada her bir seri beton grubunda aynı beton karışımından tek seferde alınan betonlar kullanılmış ve toplamda 45 adet küp beton deney numunesi kullanılmıştır. (Şekil 1.3).

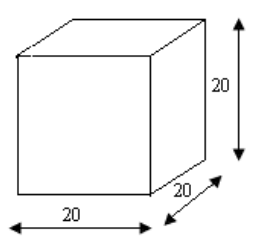

$20 \times 20 \times 20 \mathrm{~cm}$ (Standart)

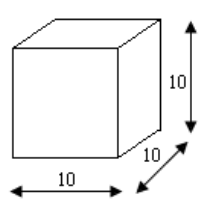

$10 \mathrm{X} 10 \mathrm{X} 10 \mathrm{~cm}$ (Standart)

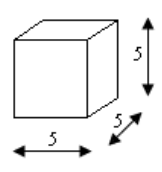

$5 \times 5 \times 5 \mathrm{~cm}$
Şekil 1.1 Küp numune kalıp şekilleri
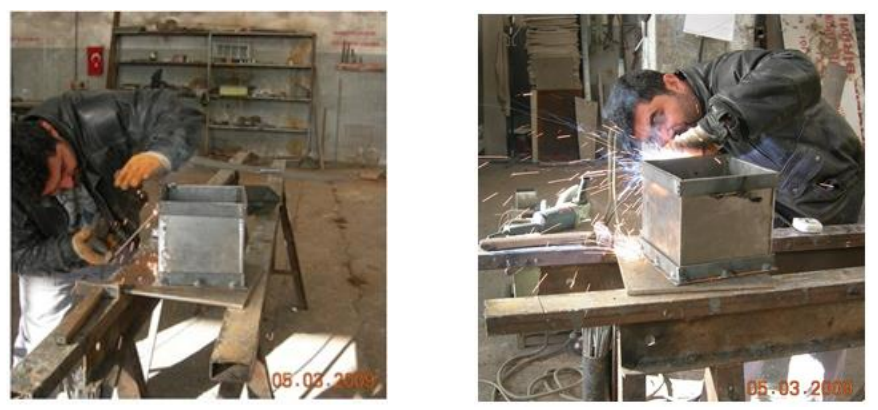

Şekil 1.2. Küp numune kalıpların hazırlanması

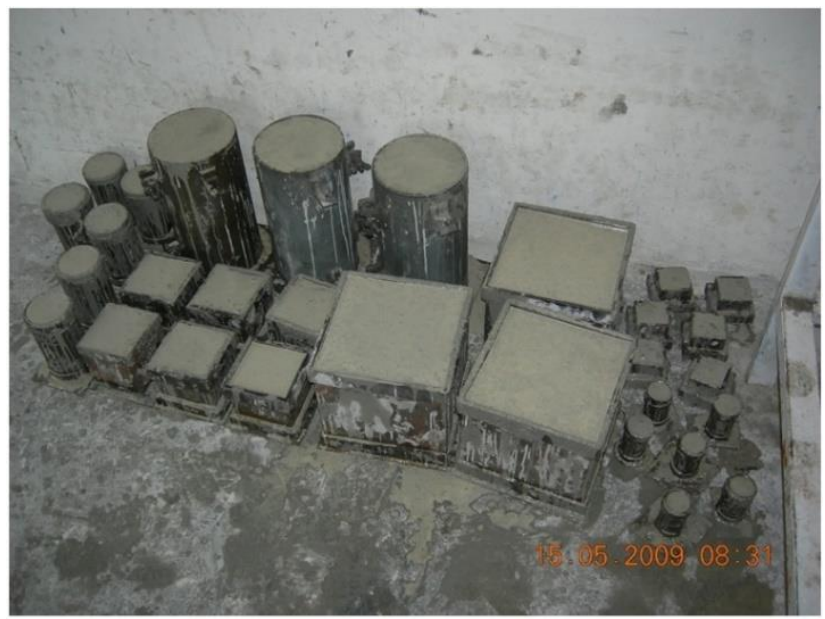

Şekil 1.3. Kalıplara yerleştirilmiş aynı seri küp beton numuneleri e-ISSN: 2148-2683

\subsection{Kullanılan Malzemeler}

Çalışmada kullanılan malzemelerin, fiziksel ve mekanik özellikleri bu kısımda açıklanmıştır.

\subsection{1. Çimento}

Deneylerde kalite standardı PÇ 42,5 ve PÇ 32,5 olan çimentolar kullanılmıştır. Kullanılan çimentolar TS EN 196 -1 standardındadır.

Tablo 2.1. Çimentonun fiziksel özellikleri

\begin{tabular}{|l|c|c|}
\hline Çimentonun Cinsi & CEM I 42,5 R & CEM II/B-P 32,5 R \\
\hline Özgül Ağırlık $\left(\mathrm{g} / \mathrm{cm}^{3}\right)$ & 3,10 & 2,88 \\
\hline $\begin{array}{l}\text { Priz Süresi Başlangıcı } \\
\text { (dak.) }\end{array}$ & 135 & 170 \\
\hline $\begin{array}{l}\text { Priz Süresi Sonu } \\
\text { (dak.) }\end{array}$ & 200 & 240 \\
\hline Özgül Yüzey(cm $\left.{ }^{2} / g\right)$ & 3690 & 4663 \\
\hline $\begin{array}{l}\text { Hacim Genleşmesi } \\
\text { (mm) }\end{array}$ & 1 & 0 \\
\hline
\end{tabular}

\subsubsection{Agrega ve Beton Karışım Hesabı}

Bu çalışmada farklı dayanımda 5 seri betonlar kullanılmıştır. Farklı dayanımlardaki bu betonlarda kullanılan agrega çapı $d_{\max }=$ 10-16 mm arasındır. Agregaların fiziksel özellikleri ve karışıma giren mikarları tablolarda sunulmuştur.

\subsubsection{Karışıma Giren A, B, C, D, E Sınıfindaki Beton Karışım Formları}

Tablo 2.2. CUA Beton Sinıf Karışım

\begin{tabular}{|c|c|c|}
\hline $\begin{array}{c}\text { KARIŞIMA GÍREN } \\
\text { MALZEMELER }\end{array}$ & $\begin{array}{c}\text { AĞIRLIK } \\
(\mathbf{k g})\end{array}$ & $\begin{array}{c}\text { HACIM } \\
\left(\mathbf{m}^{\mathbf{3}}\right)\end{array}$ \\
\hline CEMI 42.5 & 140 & 45,75 \\
\hline CEM II 32.5 & 170 & 57,63 \\
\hline KUM & 945 & 353,07 \\
\hline MICIR NO 1 & 948 & 349,29 \\
\hline MICIR NO 2 & 0 & 0 \\
\hline SU & 181 & 181,02 \\
\hline KATKI & 3,72 & 3,23 \\
\hline HAVA & 0 & 10 \\
\hline TOPLAM & 2388 & 1000,0 \\
\hline
\end{tabular}

Tablo 2.3. CUB Beton Sinıf Karışım

\begin{tabular}{|c|c|c|}
\hline $\begin{array}{c}\text { KARISSIMA GIREN } \\
\text { MALZEMELER }\end{array}$ & $\begin{array}{c}\text { AĞIRLIK } \\
(\mathbf{k g})\end{array}$ & $\begin{array}{c}\text { HACIM } \\
\mathbf{( m}^{\mathbf{3}} \mathbf{)}\end{array}$ \\
\hline$C E M 142.5$ & 200 & 65,36 \\
\hline CEMII 32.5 & 160 & 54,24 \\
\hline KUM & 964 & 357,12 \\
\hline$M I C I R$ NO 1 & 933 & 343,57 \\
\hline$M I I R$ NO 2 & 0 & 0 \\
\hline SU & 165 & 165,33 \\
\hline KATKI & 5,04 & 4,38 \\
\hline HAVA & 0 & 10 \\
\hline TOPLAM & 2428 & 1000,0 \\
\hline
\end{tabular}


Tablo 2.4. CUC Beton Sinıf Karıșım

\begin{tabular}{|c|c|c|}
\hline $\begin{array}{c}\text { KARIŞIMA GiREN } \\
\text { MALZEMELER }\end{array}$ & $\begin{array}{c}\text { AĞIRLIK } \\
(\mathbf{k g})\end{array}$ & $\begin{array}{c}\text { HACiM } \\
\mathbf{( m}^{\mathbf{3}} \mathbf{)}\end{array}$ \\
\hline CEM1 42.5 & 230 & 75,16 \\
\hline CEMII 32.5 & 180 & 61,02 \\
\hline KUM & 923 & 344,72 \\
\hline MICIR NO 1 & 927 & 341,21 \\
\hline MICIR NO 2 & 0 & 0 \\
\hline SU & 163 & 162,90 \\
\hline KATKI & 5,74 & 4,99 \\
\hline HAVA & 0 & 10 \\
\hline TOPLAM & 2429 & 1000,0 \\
& & \\
\hline
\end{tabular}

Tablo 2.5. CUD Beton Sinıf Karışım

\begin{tabular}{|c|c|c|}
\hline $\begin{array}{c}\text { KARIŞIMA GİREN } \\
\text { MALZEMELER }\end{array}$ & $\begin{array}{c}\text { AĞIRLIK } \\
(\mathbf{k g})\end{array}$ & $\begin{array}{c}\text { HACIM } \\
\mathbf{( \mathbf { m }}^{\mathbf{3}} \mathbf{)}\end{array}$ \\
\hline CEMI 42.5 & 250 & 81,70 \\
\hline CEM II 32.5 & 230 & 77,97 \\
\hline KUM & 851 & 314,43 \\
\hline$M I C I R$ NO 1 & 931 & 342,94 \\
\hline$M I C I R$ NO 2 & 0 & 0 \\
\hline SU & 167 & 167,12 \\
\hline KATKI & 6,72 & 5,84 \\
\hline HAVA & 0 & 10 \\
\hline TOPLAM & 2436 & 1000,0 \\
\hline
\end{tabular}

Tablo 2.6. CUE Beton Sinıf Karışım

\begin{tabular}{|c|c|c|}
\hline $\begin{array}{c}\text { KARIŞIMA GİREN } \\
\text { MALZEMELER }\end{array}$ & $\begin{array}{c}\text { AĞIRLIK } \\
(\mathbf{k g})\end{array}$ & $\begin{array}{c}\text { HACíM } \\
\mathbf{( \mathbf { m }}^{\mathbf{3}} \mathbf{)}\end{array}$ \\
\hline CEMI 42.5 & 300 & 98,04 \\
\hline CEM II 32.5 & 250 & 84,75 \\
\hline KUM & 777 & 287,08 \\
\hline$M I C I R$ NO 1 & 921 & 339,29 \\
\hline$M I C I R$ NO 2 & 0 & 0 \\
\hline SU & 174 & 174 \\
\hline KATKI & 7,70 & 6,70 \\
\hline HAVA & 0 & 10 \\
\hline TOPLAM & 2430 & 1000,0 \\
\hline
\end{tabular}

\subsection{Betonun Yerleştirilmesi ve Kalıplardan Çıkartılması}

Deneylerde kullanılacak kalıpların iç yüzeyi kalıp ayırıcı olarak kullandığımız yağ ile ince bir tabaka halinde kaplanmıştır. (Şekil 2.1). Bu çalışmada Hazır Beton Santralinde üretilen farklı dayanımlardaki betonlar ayrı tarihlerde alınarak deneyler gerçekleştirilmiştir. Betonun kalıp içinde düzgün yerleşmesi için TS EN 12390-2 standardına uygun sıkıştırma işlemi yapılmıştır. (Şekil 2.1).
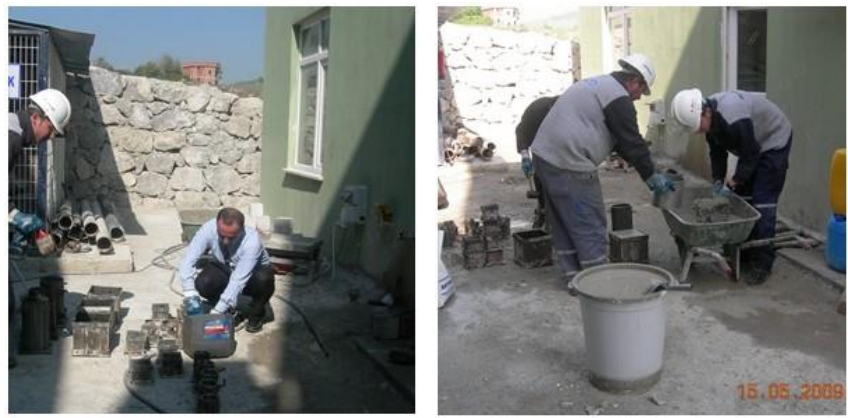

Şekil 2.1.Şantiyede Beton Küp Numune Alma
Betonun döküm işleminden sonra 28 gün süreyle $20 \pm 2^{\circ} \mathrm{C}$ 'de kür havuzuna alınmıştır. 28. gün akabinde kür havuzundan alınan numuneler hava kurusu hale gelene kadar bekletilmiş ve numuneler deneysel çalışmalara hazır hale getirilmiştir. Yapılan bu deney çalışmalarını içeren resimler Şekil 2.2'de topluca sunulmuştur.
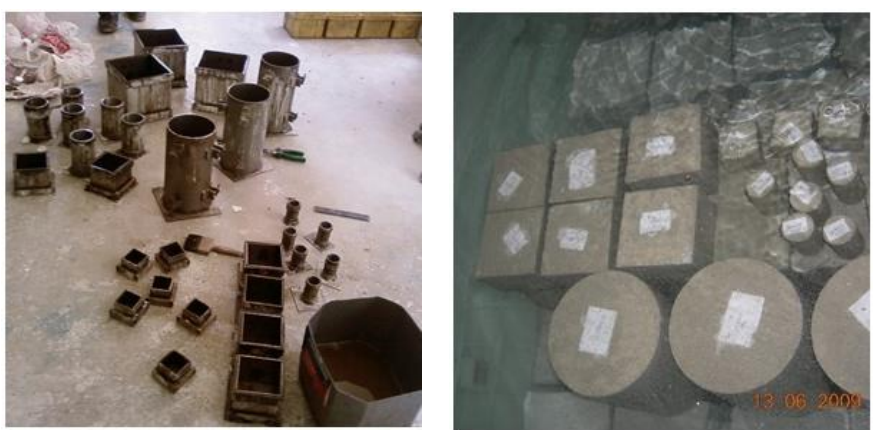

Şekil 2.2 Betonun Kalıba Yerleştirilmesi ve Kürü

\subsection{Deney Numunelerinin Yüklenmesi}

A, B, C, D, E olarak isimlendirilen farklı boy ve dayanımlardaki beton küp deney numunelerinin gerilme basınç deneylerinde 500 tonluk ve 200 tonluk kapasiteli beton pres makinaları kullanılmıştır. (Şekil 2.3 ve 2.4).

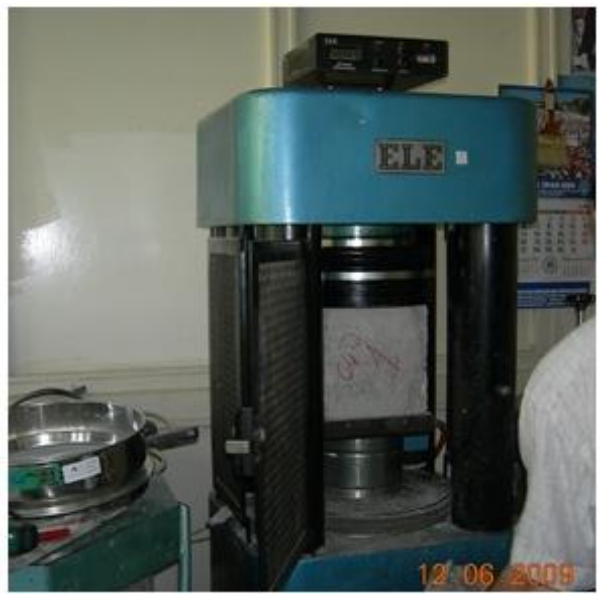

Şekil 2.3.ELE marka (500ton) beton pres makinesi

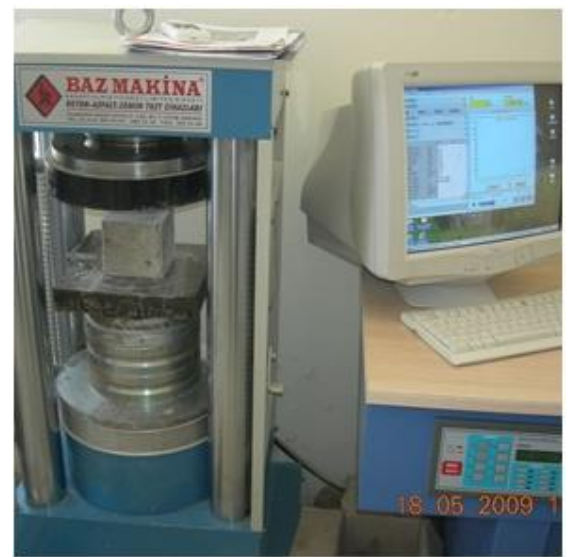

Şekil 2.4 BAZ marka (200ton) beton pres makinesi 


\subsection{Metot}

\subsubsection{Betonun Boyut Etkisi Bă̆ıntılart}

Betonun heterojen yapısı, LEKM teorisi ve Weibull'un olasılık teorisi ile tam olarak uyuşmamaktadır. Bazant ve Carpinteri tarafindan betona uygun yöntemler geliştirilmiştir. (Bazant,1998; Bazant vd., 1987; Carpinteri, 1988; Carpinteri vd., 1994).

\subsubsection{Bazant'ın Boyut Etkisi Bağıntısı}

Basitçe boyut etkisi bağıntısı Bazant tarafından çok sayıda deneysel ve analitik çalışmalar sonucunda önerilmiştir. (Bazant vd.,1998; Aydın,2010; Bazant ve Sun,1987).

$$
\sigma_{N}=\frac{B f_{t}}{\sqrt{1+D / D_{0}}}
$$

$\mathrm{f}_{\mathrm{t}}$ : malzemenin çekme gerilmesi,

$B$ : boyutsuz bir sabit,

$D_{0}$ : birimi uzunluk olan bir sabittir.

$B$ ve $D_{0}$ : malzemenin geometrisine ve kırılma özelliklerine bağlı birer sabittir.

Bu iki sabit malzeme boyutundan bağımsızdır.

Bazant'1n önerdiği boyut etkisi eşitliğinde Eş. 3.1 için, yap1 çok küçük $D<<D_{o}$ ise, $\beta=D / D_{o}$ değeri birin yanında küçük olduğundan göz önüne alınmaz. $\sigma_{N}=B f_{t}$ olur ki göçme gerilmesi plastik limit analizi ya da emniyet gerilmeleri yöntemi ile analiz edilmektedir.

Eğer yapı çok büyük ise $\left(D>>D_{o}\right)$ bir değeri $\beta$ değeri yanında çok küçüktür, $\sigma_{N}=B f_{t} \beta^{-1 / 2}$ olur.

Yani, kırılma gerilimi lineer elastik kırılma mekaniği ile analiz edilir.

Logaritmik eksende -1/2 eğimli bir doğru olarak Şekil 3.1'de gösterilmiştir.

Denklem 3.1 sadece aynı betondan yapılmış ve aynı maksimum agrega boyutunu içeren yapılara uygulanabilir.

$\beta \gg>1$ ise lineer elastik kırılma mekaniği uygulanır.

$\beta<1$ ise plastik limit analiz uygulanır.

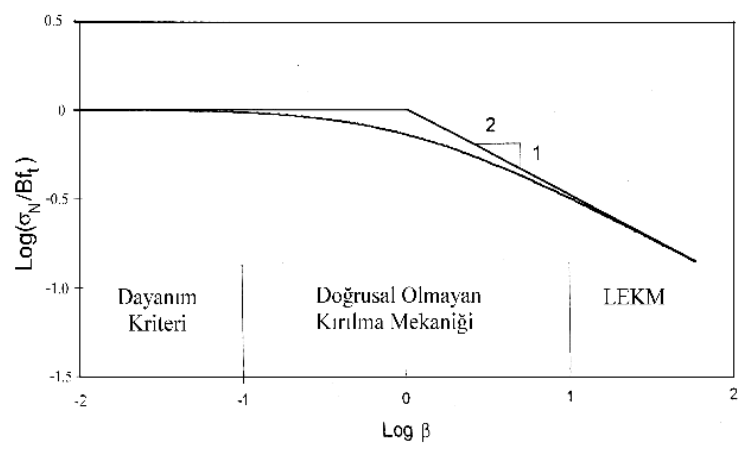

Şekil 3.1 Boyut etkisinin logaritmik ölçekte gösterimi

$\beta<0.1$ ise plastik limit analiz, $0.1<\beta<10$ ise nonlineer kırılma mekaniği, $\beta>10$ ise lineer elastik kırılma mekaniği (LEKM) geçerlidir.
Bazant'ın yaklaşık boyut etkisi denklemi Eş. (3.1) ayarlanarak, bilinmeyen malzeme sabitleri $B$ ve $D_{o}$ lineer regresyon ile elde edilebilir.

\subsubsection{Bazant'ın Doğrusal I Analizi}

Bazant'1n eşitliğine doğrusal I regresyon analizi;

$\sigma_{N}$ : nominal gerilme

D: karakteristik boyut

Doğrusal analiz I işlem sonucu

$$
\begin{aligned}
& \sigma_{N}=\frac{B f_{t} \longrightarrow}{\sqrt{1+D / D_{0}}} \text { Eş. (3.1) } \\
& \frac{1+D / D_{0}}{B^{2} f_{t}^{2}}=\frac{1}{\sigma_{N}{ }^{2}} \text { Şeklinde yazılıp, } \\
& \frac{1}{B^{2} f_{t}^{2}}+\frac{1}{B^{2} f_{t}^{2}} \frac{D}{D_{0}}=\frac{1}{\sigma_{N}{ }^{2}} \text { Denklemine dönüştürülürse }
\end{aligned}
$$

(Şekil 3.2) deki gibi eğimi $\mathrm{A}$ olan $\mathrm{Y}=\mathrm{AX}+\mathrm{C}$ gibi bir doğru olur.

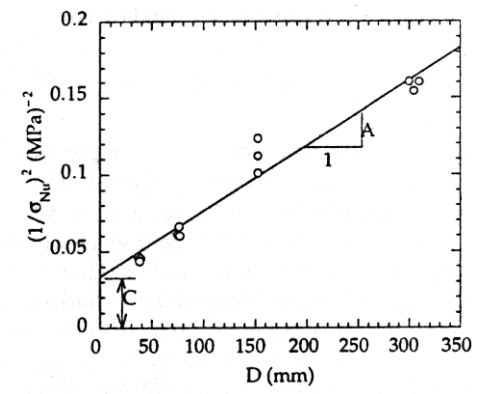

Şekil 3.2 Doğrusal Analiz I

Eş. 3.1 bağıntısı, biçiminde düzenlenir ise

$X=D, \quad Y=\left(\frac{1}{\sigma_{N}^{2}}\right), B f_{t}=1 / \sqrt{ } C, D_{0}=C / A$

Kırılma mekaniği parametreleri

$$
K_{I C}=k_{0} B f_{t} \sqrt{D_{0}} \quad G_{f}=\frac{k_{0}}{2 k_{o}^{\prime}} D_{0} \quad C_{f}=\frac{\left(B f_{t}\right)^{2} D_{0} k_{0}{ }^{2}}{E}
$$

Eşitlikler yazılırsa,

$$
\begin{array}{ll}
K_{I c}=k_{0} \frac{1}{\sqrt{A}}, & G_{f}=\frac{k_{0}^{2}}{E} \frac{1}{A} \\
c_{f}=\frac{k_{0}}{2 k_{0}^{\prime}} \frac{C}{A} &
\end{array}
$$

\subsubsection{Bazant' 'ın Doğrusal II Analizi}

Doğrusal II analiz: Eş. 3.1 bağıntısı, $Y^{\prime}=A X^{\prime}+C^{\prime}$ şeklinde düzenlenir ise (Şekil 3.3); 
$X^{\prime}=1 / D, Y^{\prime}=\frac{1}{\sigma_{N}^{2} D}$

$B f_{t}=1 / \sqrt{ } \mathrm{A}^{\prime}$

$D_{0}=\mathrm{A}^{\prime} / \mathrm{C}^{\prime}$

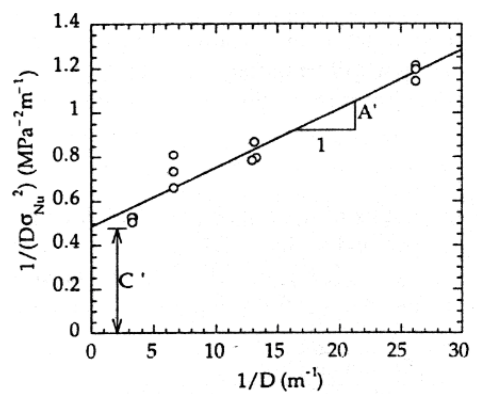

Şekil 3.3. Doğrusal Analiz II

Doğrusal analiz II sonucunda $K_{\mathrm{Ic}}$, $\mathrm{G}_{\mathrm{f}}$ ve $\mathrm{c}_{\mathrm{f}}$ değerleri de aşağıdaki şekilde bulunmaktadır:

$K_{I c}=k_{0} \frac{1}{\sqrt{C^{\prime}}}, G_{f}=\frac{k_{0}^{2}}{E^{\prime}} \frac{1}{C^{\prime}}, \quad c_{f}=\frac{k_{0}}{2 k_{0}^{\prime}} \frac{A^{\prime}}{C^{\prime}}$

$\omega_{A}^{2}=\frac{1}{A^{2}} \frac{\chi^{2} \sum}{(n-2) \Delta}, \omega_{C}^{2}=\frac{1}{C^{2}} \frac{\chi^{2} \sum_{x x}}{(n-2) \Delta}$,

$m^{2}=\frac{(n-1) \chi^{2} \sum\left(\sum_{x}\right)^{2}}{(n-2) \Delta\left(\sum_{y}\right)^{2}}$

$\chi^{2}=\sum_{y y}-A \sum_{x y}-C \sum_{y}$

$\omega_{K_{\text {Ic }}}=\frac{1}{2} \omega_{A}$

\subsubsection{Doğrusal Olmayan Analiz}

Bazant'in doğrusal olmayan regresyon analizi;

$\sigma_{N}$ : nominal gerilme

D: karakteristik boyuttur.

$D_{0}$ ve $B f_{t}$ değerlerini doğrusal değer olarak gösterilir.

Eş. 3.1'in her iki tarafının doğal logaritması alınır ve düzenlenirse:

$$
\ln \sigma_{N}=\ln \frac{B f_{t} \sqrt{D_{0}}}{\sqrt{D_{0}+D}}
$$

$K_{I c}, G_{f}$ ve $c_{f}$ değerleri analiz sonucu;

$$
K_{I c}=k_{0} M, \quad G_{f}=\frac{k_{0}^{2}}{E} M^{2}, \quad c_{f}=\frac{k_{0}}{2 k_{0}^{\prime}} N
$$

\subsubsection{Carpinteri'nin Çok Çatlaklı Boyut Etkisi Bağıntısı}

(Carpinteri, 1988), çatlak yüzeyindeki en yüksek yükte meydana gelen hasarı fraktal geometri ile modelleyerek boyut etkisi kavramına geometrik olarak yaklaşmıştır. Teori temel olarak numunenin homojenlik derecesine dayanmaktadır. Küçük beton yapılarda, yapı boyutunun yanında agrega boyutu da ihmal edilemeyeceğinden homojenlik minimum düzeydedir.

Ölçekleme Yasasının (MFSL) analitik ifadesi aşağıdaki gibidir (3.19):

$$
\sigma_{N}=\left(C+\frac{A}{d}\right)^{0,5}
$$

$\sigma_{\mathrm{N}}=$ Nominal çekme dayanımı

$\mathrm{C}=$ Gerilme karesinin fiziksel boyutları ile sabittir.

$\mathrm{A}=$ Gerilim-yoğunluk faktörünün karesinin fiziksel boyutları ile sabittir.

$\mathrm{d}=$ Karakteristik yapı boyutu

Bazant'ın boyut etkisi teorisi belirli bir boyut aralığında geçerliliği olmasına karşın, Carpinteri'nin fraktal yaklaşımı Bazant'ın aksine sınırsız bir boyut aralığında geçerliliği kabul edilmiştir.

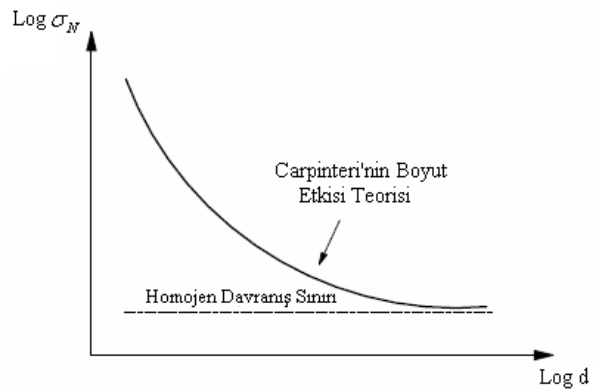

Şekil 3.4.Carpinteri'nin boyut etkisi teorisi

Carpinteri'ye göre, eleman boyutu küçüldükçe nominal gerilmeler sonsuza gider. Eleman boyutu arttıkça, nominal gerilim sabit bir değere yaklaşır (Carpinteri vd.,1994).

\section{Araştırma Sonuçları ve Tartışma}

\subsection{CUA-CUB-CUC-CUD-CUE Beton Küp Numuneleri Basınç Dayanım Değerleri}

Küp numunelerde beton press makinaları sonucunda okunan dayanım değerleri Tablo 3.1'de sunulmuştur. Tablolar incelendiğinde beton küp numuneler de boyut arttıkça ortalama dayanımların düştüğü açıkça görülebilmektedir. 
Tablo 3.1 Beton Küp Deney Numune Grubu Basınç Dayanım Değerleri

\begin{tabular}{|c|c|c|c|c|c|}
\hline $\begin{array}{c}\text { Numune } \\
\text { Boyutu } \\
\text { (dxdxd) } \\
\text { (cm) }\end{array}$ & $\begin{array}{l}\text { Beton } \\
\text { Sinifi }\end{array}$ & $\begin{array}{l}\text { Küp } \\
\text { No }\end{array}$ & $\begin{array}{l}\text { Göçme } \\
\text { Yükü(N) }\end{array}$ & $\begin{array}{r}\text { Dayanım } \\
\text { (Mpa) }\end{array}$ & $\begin{array}{l}\text { Ortalame } \\
\text { Dayanım }\end{array}$ \\
\hline \multirow{3}{*}{$20 \times 20 \times 20$} & \multirow{9}{*}{ 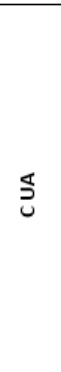 } & 1 & 11193500 & 29,84 & \\
\hline & & 2 & 1271500 & 31,79 & 28,76 \\
\hline & & 3 & \begin{tabular}{|l}
986100 \\
\end{tabular} & 24,65 & \\
\hline \multirow{3}{*}{$10 \times 10 \times 10$} & & 4 & 239800 & 23,98 & \multirow{3}{*}{30,48} \\
\hline & & 5 & 328800 & 32,88 & \\
\hline & & 6 & 345700 & 34,57 & \\
\hline \multirow{3}{*}{$5 \times 5 \times 5$} & & 7 & 78900 & 31,56 & \multirow{3}{*}{32,25} \\
\hline & & 8 & 81100 & 32,44 & \\
\hline & & 9 & 81900 & 32,76 & \\
\hline
\end{tabular}

\begin{tabular}{|c|c|c|c|c|c|}
\hline $\begin{array}{c}\text { Numune } \\
\text { Boyutu } \\
(\mathrm{dxdxd}) \\
(\mathrm{cm})\end{array}$ & $\begin{array}{l}\text { Beton } \\
\text { Sinifi }\end{array}$ & Küp & $\begin{array}{l}\text { Göçme } \\
\text { Yükü(N) }\end{array}$ & $\begin{array}{c}\text { Dayanım } \\
\text { (Mpa) }\end{array}$ & $\begin{array}{l}\text { Ortalama } \\
\text { Dayanım }\end{array}$ \\
\hline \multirow{3}{*}{$20 \times 20 \times 20$} & \multirow{9}{*}{ 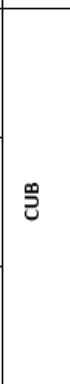 } & 1 & 1788300 & 44,71 & \\
\hline & & 2 & 1469200 & 36,73 & 37,23 \\
\hline & & 3 & 1209500 & 30,24 & \\
\hline \multirow{3}{*}{$10 \times 10 \times 10$} & & 4 & 362900 & 36,29 & \multirow{3}{*}{40,50} \\
\hline & & 5 & 411200 & 41,12 & \\
\hline & & 6 & 4441000 & 44,1 & \\
\hline \multirow{3}{*}{$5 \times 5 \times 5$} & & 7 & 110000 & 44 & \multirow{3}{*}{46,80} \\
\hline & & 8 & 120000 & 48 & \\
\hline & & 9 & 121000 & 48,4 & \\
\hline
\end{tabular}

\begin{tabular}{|c|c|c|c|c|c|}
\hline $\begin{array}{c}\text { Numune } \\
\text { Boyutu } \\
(\mathrm{dxdxd}) \\
(\mathrm{cm})\end{array}$ & $\begin{array}{l}\text { Beton } \\
\text { Sinifi }\end{array}$ & Küp & $\begin{array}{l}\text { Göçme } \\
\text { Yükü(N) }\end{array}$ & $\begin{array}{c}\text { Dayanım } \\
\text { (Mpa) }\end{array}$ & $\begin{array}{l}\text { Ortalama } \\
\text { Dayanım }\end{array}$ \\
\hline \multirow{3}{*}{$20 \times 20 \times 20$} & \multirow{9}{*}{ ૫ } & 1 & 1239000 & 30,98 & \\
\hline & & 2 & 1494000 & 37,35 & 32,83 \\
\hline & & 3 & 1206000 & 30,15 & \\
\hline \multirow{3}{*}{$10 \times 10 \times 10$} & & 4 & 466200 & 46,62 & \multirow{3}{*}{45,44} \\
\hline & & 5 & 504100 & 50,41 & \\
\hline & & 6 & 393000 & 39,3 & \\
\hline \multirow{3}{*}{$5 \times 5 \times 5$} & & 7 & 121200 & 48,48 & \multirow{3}{*}{45,81} \\
\hline & & 8 & 111000 & 44,4 & \\
\hline & & 9 & 111400 & 44,56 & \\
\hline
\end{tabular}

\begin{tabular}{|c|c|c|c|c|c|}
\hline $\begin{array}{c}\text { Numune } \\
\text { Boyutu } \\
(\mathrm{dxdxd}) \\
(\mathrm{cm})\end{array}$ & $\begin{array}{l}\text { Beton } \\
\text { Sinifi }\end{array}$ & Küp & $\begin{array}{l}\text { Göçme } \\
\text { Yükü(N) }\end{array}$ & $\begin{array}{c}\text { Dayanım } \\
\text { (Mpa) }\end{array}$ & $\begin{array}{l}\text { Ortalama } \\
\text { Dayanım }\end{array}$ \\
\hline \multirow{3}{*}{$20 \times 20 \times 20$} & \multirow{9}{*}{ ટ્ } & 1 & 1578000 & 39,45 & \\
\hline & & 2 & 1355000 & 33,88 & 35,36 \\
\hline & & 3 & 1310000 & 32,75 & \\
\hline \multirow{3}{*}{$10 \times 10 \times 10$} & & 4 & 426500 & 42,65 & \multirow{3}{*}{48,39} \\
\hline & & 5 & 471300 & 47,13 & \\
\hline & & 6 & 553800 & 55,38 & \\
\hline \multirow{3}{*}{$5 \times 5 \times 5$} & & 7 & 135000 & 54 & \multirow{3}{*}{61,48} \\
\hline & & 8 & 161000 & 64,4 & \\
\hline & & 9 & 165100 & 66,04 & \\
\hline
\end{tabular}

\begin{tabular}{|c|c|c|c|c|c|}
\hline $\begin{array}{c}\text { Numune } \\
\text { Boyutu } \\
\text { (dxdxd) } \\
(\mathrm{cm})\end{array}$ & $\begin{array}{l}\text { Beton } \\
\text { Sinıfi }\end{array}$ & Küp & $\begin{array}{l}\text { Göçme } \\
\text { Yükü(N) }\end{array}$ & $\begin{array}{c}\text { Dayanım } \\
\text { (Mpa) }\end{array}$ & $\begin{array}{l}\text { Ortalama } \\
\text { Dayanım }\end{array}$ \\
\hline \multirow{3}{*}{$20 \times 20 \times 20$} & \multirow{9}{*}{$\stackrel{山}{己}$} & 1 & 1541000 & 38,53 & \\
\hline & & 2 & 1796000 & 44,9 & 44,49 \\
\hline & & 3 & 2001000 & 50,03 & \\
\hline \multirow{3}{*}{$10 \times 10 \times 10$} & & 4 & 509900 & 50,99 & \multirow{3}{*}{54,62} \\
\hline & & 5 & 561500 & 56,15 & \\
\hline & & 6 & 567100 & 56,71 & \\
\hline \multirow{3}{*}{$5 \times 5 \times 5$} & & 7 & 124000 & 49,6 & \multirow{3}{*}{57,07} \\
\hline & & 8 & 147000 & 58,8 & \\
\hline & & 9 & 157000 & 62,8 & \\
\hline
\end{tabular}

Bazant tarafından önerilen teorideki denklemi (3.1) lineer regresyon ile düzenlendikten sonra, verilen $\mathrm{Y}=\mathrm{AX}+\mathrm{C}$ formatına getirilerek her bir beton küp numune için kırılma değerlerinin yer aldığı tablolar ve ilgili grafikler oluşturulacaktır. Boyut etkisini en net gösteren eğri Bazant'ın logaritmik eğrisidir (Şekil 3.1).

Bölüm 2.5'de açıklanan teorilere göre bağıntıların analizleri bilgisayar programı Excel ile çözümlenmiş. Programdan elde edilen lineer regrasyon analizleri sonucunda bulunan değerlerle beton küp deney numunelerinin her bir grubuna ait Doğrusal I, Doğrusal II, Doğrusal Olmayan Analizler ile, MFSL analiz sonuçları Tablo 3.2-Tablo 3.6 ve Şekiller 4.6-4.13 de verilmiştir.

\subsection{Beton Küp Numune Analiz Sonuçları}

Tablo 3.2 Boyut Etkisi Parametreleri A Deney Grubu

\begin{tabular}{|c|c|c|c|c|}
\hline & & & $\begin{array}{c}\text { Çok } \\
\text { Değişkenler }\end{array}$ & $\begin{array}{c}\text { Doğgakusal } \\
\text { Analiz I } \\
\text { Doğgut } \\
\text { Etkisi } \\
\text { Onalizi } \\
\text { Doğrusal } \\
\text { Analizan }\end{array}$ \\
\hline $\begin{array}{c}D_{0}\left(l_{c h}\right) \\
(\mathrm{mm})\end{array}$ & 515,1116 & 342,8155 & 539,269477 & 16,390 \\
\hline$A(A c)$ & $1,784 \mathrm{E}-06$ & 0,0008497 & - & 12966,36 \\
\hline$C(B c)$ & 0,0009191 & $2,478 \mathrm{E}-06$ & - & 791,0916 \\
\hline$\omega_{A}\left(\omega_{A c}\right)$ & 0,987328 & 0,1824278 & - & 0,8684 \\
\hline$\omega_{C}\left(\omega_{C c}\right)$ & 0,2535593 & 0,8273141 & - & 0,1883 \\
\hline$R$ & 0,357 & 0,900 & 0,400 & 0,39 \\
\hline$m$ & 0,5156902 & 0,4127769 & - & 0,3943 \\
\hline$B f_{t}(M p a)$ & 32,985627 & 34,306752 & 33,3194675 & 0,3718 \\
\hline
\end{tabular}

Tablo 3.3 Boyut Etkisi Parametreleri B Deney Grubu

\begin{tabular}{|c|c|c|c|c|}
\hline Değişkenler & $\begin{array}{c}\text { Doğrusal } \\
\text { Analiz I }\end{array}$ & $\begin{array}{l}\text { Doğrusal } \\
\text { Analiz II }\end{array}$ & $\begin{array}{c}\text { Doğrusal } \\
\text { Olmayan } \\
\text { Analiz }\end{array}$ & $\begin{array}{c}\text { Çok } \\
\text { Çatlaklı } \\
\text { Boyut } \\
\text { Etkisi } \\
\text { Analizi }\end{array}$ \\
\hline$D_{0}\left(l_{c h}\right)(\mathrm{mm})$ & 185,87776 & 143,10058 & 224,402221 & 45,2191 \\
\hline$A(A c)$ & $2,048 \mathrm{E}-06$ & 0,0003447 & - & 51959,7 \\
\hline$C(B c)$ & 0,0003808 & $2,409 \mathrm{E}-06$ & - & 1149,06 \\
\hline$\omega_{A}\left(\omega_{A c}\right)$ & 0,4632219 & 0,1870649 & - & 0,3683 \\
\hline$\omega_{C}\left(\omega_{C C}\right)$ & 0,329671 & 0,3541219 & - & 0,2203 \\
\hline$R$ & 0,632 & 0,896 & 0,679 & 0,72 \\
\hline$m$ & 0,505233 & 0,3308983 & - & 0,3598 \\
\hline$B f_{t}(M p a)$ & 51,247984 & 53,860777 & 50,2643949 & 0,3869 \\
\hline
\end{tabular}


Tablo 3.4 Boyut Etkisi Parametreleri C Deney Grubu

\begin{tabular}{|c|c|c|c|c|}
\hline Değişkenler & $\begin{array}{c}\text { Doğrusal } \\
\text { Analiz I }\end{array}$ & $\begin{array}{l}\text { Doğrusal } \\
\text { Analiz II }\end{array}$ & $\begin{array}{c}\text { Doğrusal } \\
\text { Olmayan } \\
\text { Analiz }\end{array}$ & $\begin{array}{c}\text { Çok } \\
\text { Çatlaklı } \\
\text { Boyut } \\
\text { Etkisi } \\
\text { Analizi }\end{array}$ \\
\hline$D_{0}\left(l_{c h}\right)(\mathrm{mm})$ & 75,20192 & 137,2212 & 675,1023 & 53,9043 \\
\hline$A(A c)$ & $3,36 \mathrm{E}-06$ & 0,00034 & - & 58206 \\
\hline$C(B c)$ & 0,000252 & $2,48 \mathrm{E}-06$ & - & 1079,8 \\
\hline$\omega_{A}\left(\omega_{A c}\right)$ & 0,240937 & 0,1961 & - & 0,43686 \\
\hline$\omega_{C}\left(\omega_{C c}\right)$ & 0,423832 & 0,355973 & - & 0,3115 \\
\hline$R$ & 0,843 & 0,887 & 0,756 & 0,65 \\
\hline$m$ & 0,414374 & 0,341401 & - & 0,4771 \\
\hline$B f_{t}(M p a)$ & 62,93914 & 54,21656 & 44,35814 & 0,3715 \\
\hline
\end{tabular}

Tablo 3.5 Boyut Etkisi Parametreleri D Deney Grubu

\begin{tabular}{|c|c|c|c|c|}
\hline Değişkenler & $\begin{array}{c}\text { Doğrusal } \\
\text { Analiz I }\end{array}$ & $\begin{array}{l}\text { Doğrusal } \\
\text { Analiz II }\end{array}$ & $\begin{array}{c}\text { Doğrusal } \\
\text { Olmayan } \\
\text { Analiz }\end{array}$ & $\begin{array}{c}\text { Çok } \\
\text { Çatlaklı } \\
\text { Boyut } \\
\text { Etkisi } \\
\text { Analizi }\end{array}$ \\
\hline$D_{0}\left(l_{c h}\right)(\mathrm{mm})$ & 23,15908 & 25,49656 & 23,5552 & 308,2976 \\
\hline$A(A c)$ & $3,64 \mathrm{E}-06$ & $9,12 \mathrm{E}-05$ & - & 166240,4 \\
\hline$C(B c)$ & $8,44 \mathrm{E}-05$ & $3,58 \mathrm{E}-06$ & - & 539,2206 \\
\hline$\omega_{A}\left(\omega_{A c}\right)$ & 0,156655 & 0,578811 & - & 0,1841 \\
\hline$\omega_{C}\left(\omega_{C c}\right)$ & 0,894832 & 0,195226 & - & 0,751 \\
\hline$R$ & 0,924 & 0,546 & 0,918 & 0,898 \\
\hline$m$ & 0,369699 & 0,375333 & - & 0,407 \\
\hline$B f_{t}(M p a)$ & 108,8559 & 104,726 & 108,9853 & 0,6416 \\
\hline
\end{tabular}

Tablo 3.6 Boyut Etkisi Parametreleri E Deney Grubu

\begin{tabular}{|c|c|c|c|c|}
\hline & & & Çok \\
Değişkenler & $\begin{array}{c}\text { Doğrusal } \\
\text { Analiz I }\end{array}$ & $\begin{array}{c}\text { Doğrusal } \\
\text { Analiz II } \\
\text { Çatlaklı } \\
\text { Boyut } \\
\text { Elmayal } \\
\text { Elmisi } \\
\text { Analiz } \\
\text { Analizi }\end{array}$ \\
\hline$D_{0}\left(l_{c h}\right)(\mathrm{mm})$ & 154,6337 & 223,23472 & 273,6553 & 41,9791 \\
\hline$A(\mathrm{Ac})$ & $1,45 \mathrm{E}-06$ & 0,0002543 & - & 77750,61 \\
\hline$C(B c)$ & 0,000224 & $1,139 \mathrm{E}-06$ & - & 1852,127 \\
\hline$\omega_{A}\left(\omega_{A c}\right)$ & 0,339947 & 0,2080652 & - & 0,41064 \\
\hline$\omega_{C}\left(\omega_{C c}\right)$ & 0,290821 & 0,6144411 & - & 0,22804 \\
\hline$R$ & 0,743 & 0,876 & 0,710 & 0,677 \\
\hline$m$ & 0,413478 & 0,4252256 & - & 0,381 \\
\hline$B f_{t}(\mathrm{Mpa})$ & 66,86829 & 62,703607 & 61,23312 & 0,4252 \\
\hline
\end{tabular}

\subsubsection{Boyut Etkisi Eğrileri: Doğrusal I Analiz Sonuçları}

Doğrusal I analiz sonuçları logaritmik eksen takımlı boyut etkisi eğrileri Şekil 4.6'da gösterilmiştir. Her bir seri betona ait boyut etkisi eğrileri de toplu olarak Şekil 4.7'de gösterilmiştir.

LEKM'de boyut etkisi kuvvetlice görülür. Gerçekte betonun nominal dayanımı, bu iki ideal durum arasındadır. Eleman boyutları ve gevreklik arttıkça, LEKM'ne yaklaşılmaktadır.
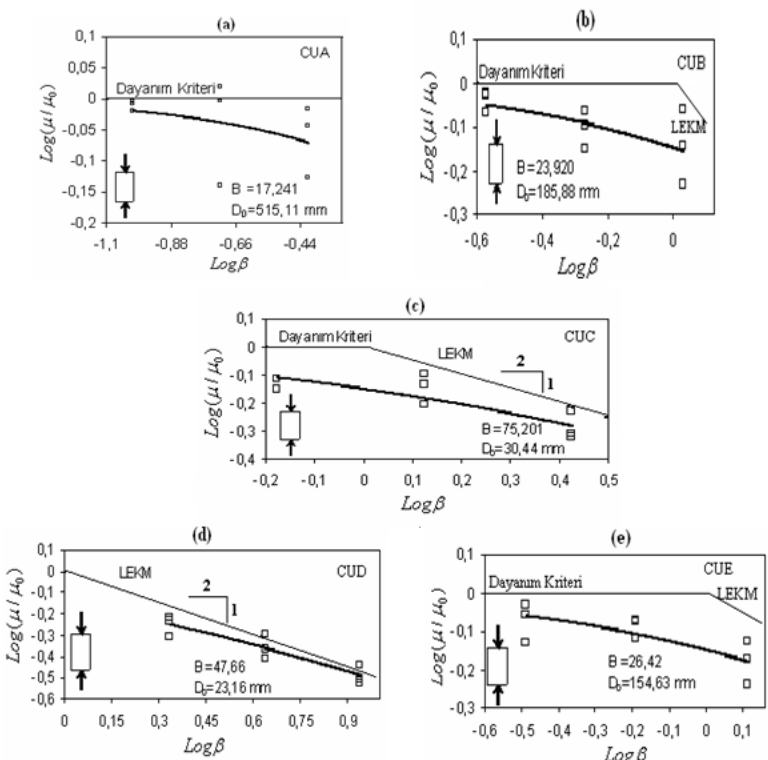

Şekil 4.6 Bazantın Doğrusal I Analiz Sonucu logaritmik eksen takımlı boyut etkisi eğrileri

Şekil 4.6 ve Şekil 4.7'deki eğrilerde kullanılan $\mu$ değişkeni, boyut etkisi analizinde kullanılan nominal gerilim değeridir.

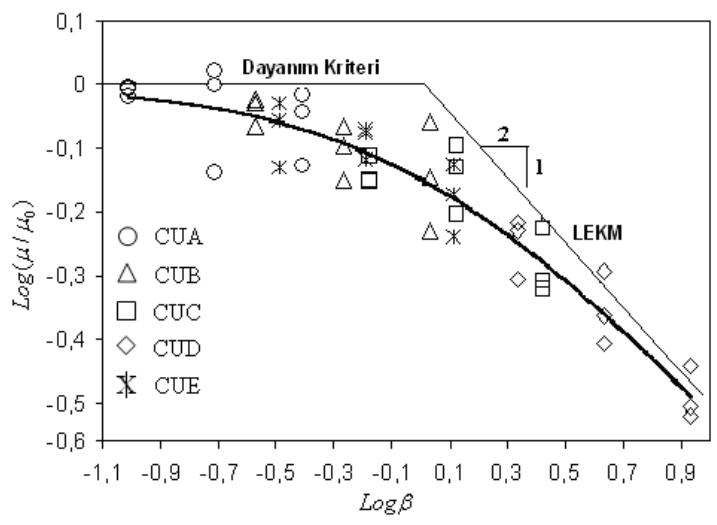

Şekil 4.7. Beton Küp Numunelerin Doğrusal I Analiz Sonucu Toplu Boyut Etkisi Eğrisi

\subsubsection{Boyut Etkisi Ĕgrileri: Doğrusal II Analiz Sonuçlart}

Bazant'ın Doğrusal II analiz sonuçları logaritmik eksen takımlı boyut etkisi eğrileri Şekil 4.8'de gösterilmiştir. Her bir seri betona ait boyut etkisi eğrileri de toplu olarak Şekil 4.9'de gösterilmiştir. 

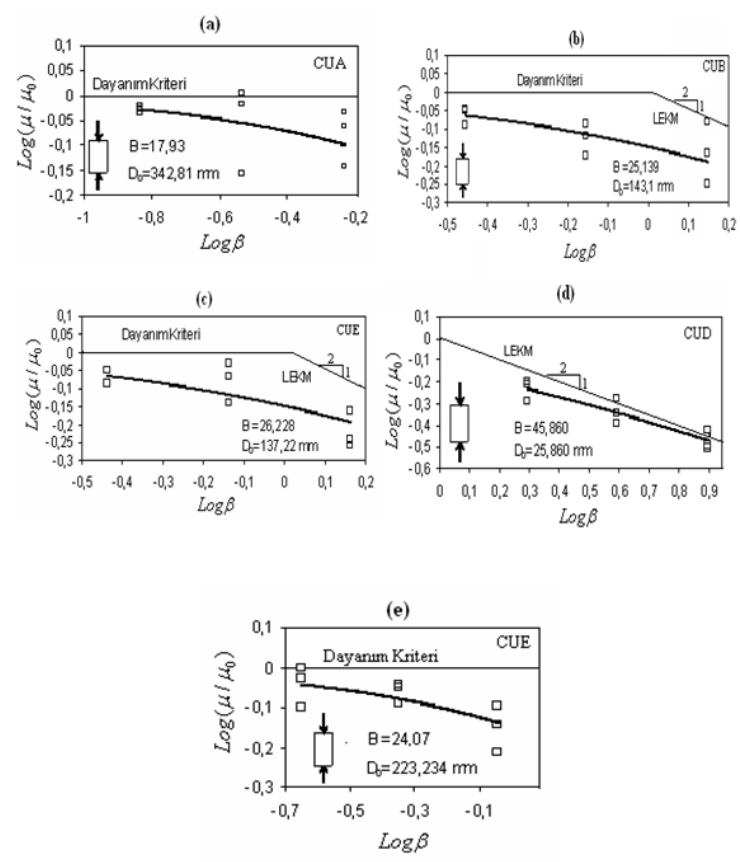

Şekil 4.8 Bazantın Doğrusal II Analiz Sonucu logaritmik eksen takımlı boyut etkisi eğrileri

Şekil 4.8 ve 4.9'daki eğrilerde kullanılan $\mu$ değişkeni, boyut etkisi analizinde kullanılan nominal gerilim değeridir.

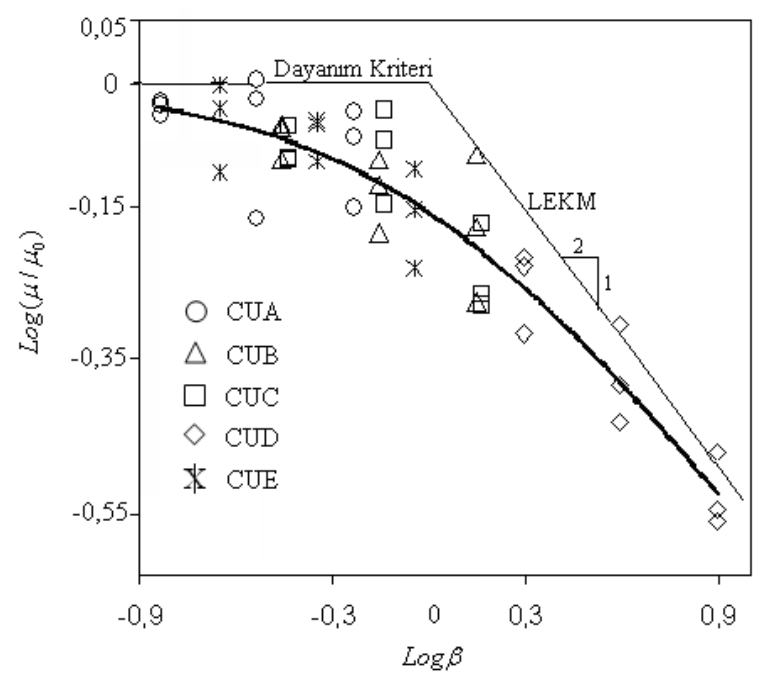

Şekil 4.9. Beton Küp Numunelerin Doğrusal II Analiz Sonucu Toplu Boyut Etkisi Eğrisi

\subsubsection{Boyut Etkisi Ĕ̆rileri: Doğrusal Olmayan Analiz Sonuçlart}

Bazant'ın doğrusal olmayan analiz sonuçları logaritmik eksen takımlı boyut etkisi eğrileri Şekil 4.10'da gösterilmiştir. Her bir seri betona ait boyut etkisi eğrileri de toplu olarak Şekil 4.11'de gösterilmiştir.
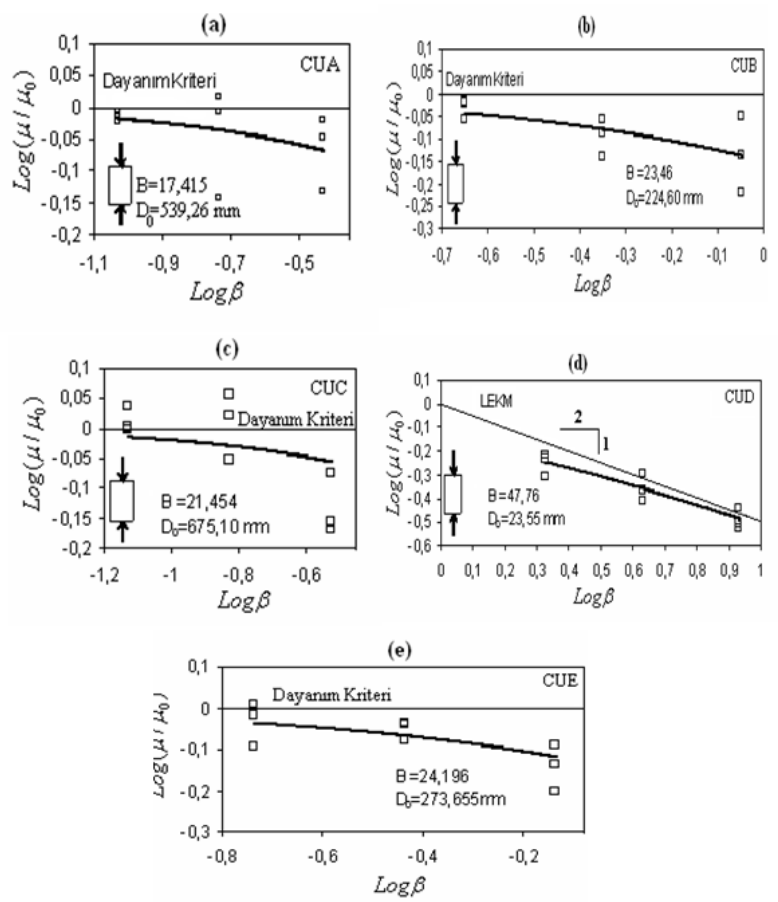

Şekil 4.10 Bazantın Doğrusal Olmayan Analiz Sonucu logaritmik eksen takımlı boyut etkisi eğrileri

Şekil 4.10 ve 4.11 deki eğrilerde kullanılan $\mu$ değişkeni, boyut etkisi analizinde kullanılan nominal gerilim değeridir.

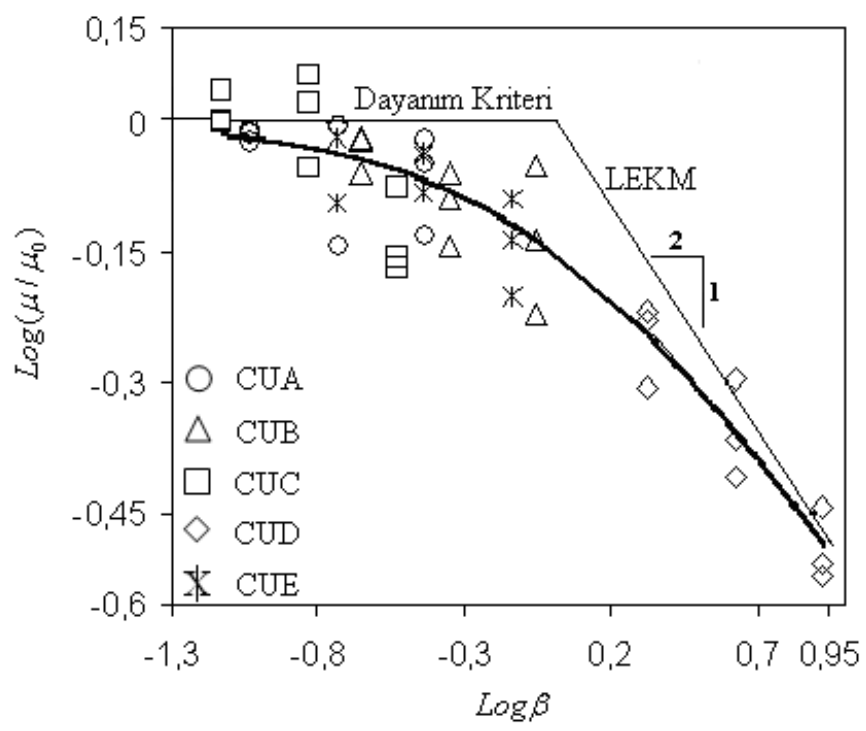

Şekil 4.11. Beton Küp Numunelerin Doğrusal Olmayan Analiz Sonucu Toplu Boyut Etkisi Eğrisi 


\subsubsection{Carpinteri Çok Çatlaklı Boyut Etkisi Analiz Sonucu Ĕgrileri}
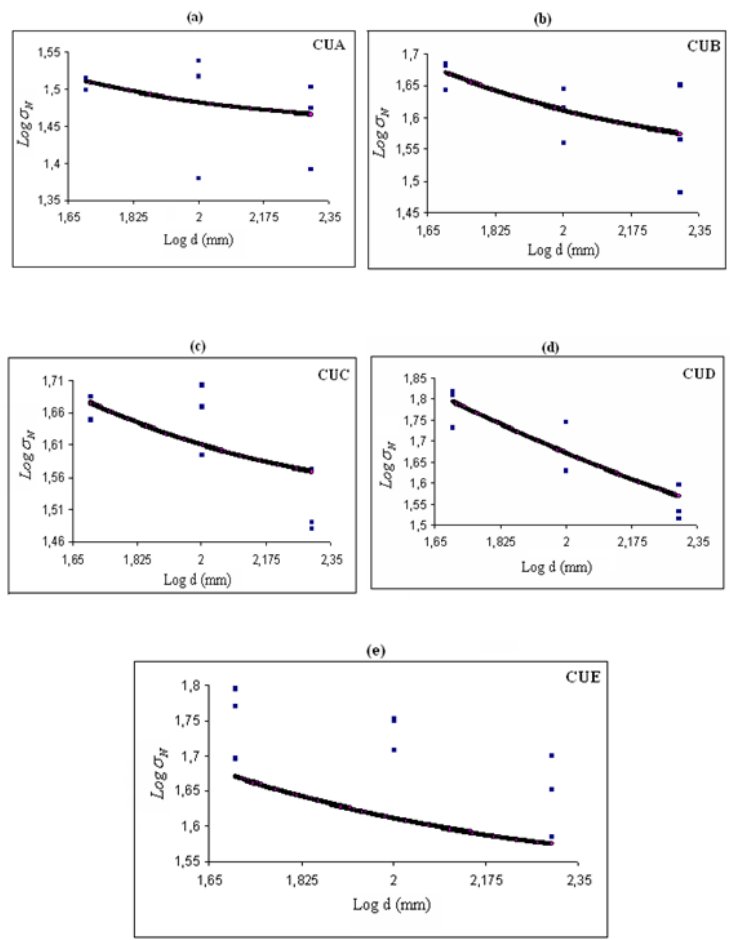

Şekil 4.12 Carpinteri (MFSL) Analizi Sonucu Logaritmik Eksen Takımlı Boyut Etkisi Eğrileri

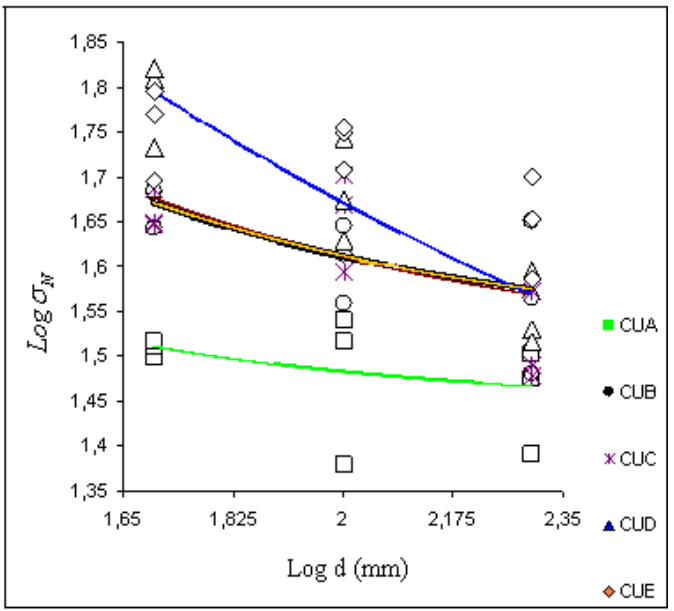

Şekil 4.13 Carpinteri (MFSL) Analizi Sonucu Logaritmik Eksen Takımlı Toplu Boyut Etkisi Eğrileri

\section{Sonuç}

Yapılan bu deneysel çalışmanın sonuçlarına dayanarak, aşağıdaki çıkarımlar elde edilmiştir.

Farklı dayanımlara sahip küp beton numunelerin eksenel basınç yükü altında kırılma basınç gerilmeleri deneysel olarak bulunmuş ve bu sonuçlara göre kırılma yüklerinde boyut etkisi parametreleri hesaplanarak eğriler çizilmiştir.

— Boyut etkisinin varlığı, farklı büyüklükteki küp örnekleriyle yapılan deneylerden elde edilen sonuçlardan açıkça görülmüştür.
Yani, artan boyut ile gerilme azalır. Küp numunelerde en yüksek mukavemet değerinin $5 \times 5 \times 5$ cm'lik küp numunelerde, en düşük mukavemet değerinin ise 20x20x20 cm'lik küp numunelerde ulaşılmıştır.

* Elde edilen bu sonuçlar ışı ğında küp numune basınç dayanm sonuçları beklendiği gibi Bazant ve Carpinteri tarafindan önerilen boyut etkisi yasası ile uyumludur.

* Analiz sonuçlarına göre çizelgeler ve eğriler incelendiğinde, küp numunelerinin ortalama dayanım sonuçlarına bakılarak boyut etkisinin varlığı görülmektedir. Regresyon analizi sonucunda, Bazant ve Carpinteri'nin boyut etkisi teorisine uygun küp örneklerinin ortalama dayanım sonuçlarından ve regresyon eğrilerinden de anlaşılacağı gibi boyut etkisinin varlığına ulaşılmıştır.

* Basınç dayanımı numune boyutuna ve şekline göre değişir. $\mathrm{Bu}$ değişimde numune boyutunun artmasıyla mukavemetin azaldığ 1 gözlemlenmiş ancak bu görüşün aksine küçük boyutlu küp numunelerde değerler elde edilmiştir. Beton sınıfı arttıkça numune boyutları arasındaki dayanım farkı azalmaktadır.

Basınç testlerinde küçük boyutlu numunelerin kullanılmasının avantajlarının yanı sıra yüksek dayanımlı betonlarda kullanılması diğer boyutlu numunelere göre daha fazla etkiye maruz kalmasina neden olabilir.

\section{Teșekkür}

$\mathrm{Bu}$ çalışmanın deneysel çalışmalarına katkı sağlayan Samsun Betonsa Hazır Beton Santrali Laboratuvar çalışanlarına, Karayolları 7.Şube Müdürlüğü Araştırma Laboratuvarı çalışanlarına teşekkür ederim.

\section{Kaynakça}

Koç, V., Şener, S., (2003). "Lifli Beton Çift Konsolun Basınç Göçmesinde Boyut Etkisi”, Yapı Mekaniği Laboratuarları Toplantısı II, TÜBİTAK, Konya,169-172.

Koç V., Şener S., (2003). "Hafif ve normal betondan yapılmış çift konsol numunelerin basıç göçmesinde boyut etkisi", Türkiye İnşaat Mühendisliği XVII. Teknik Kongre ve Sergisi, İstanbul, 137-141,

Koç V., Şener S., (2004). "Eksenel doğrultuda basınç yüklü çift konsollarda boyut etkisi", Advances in Civil Engineering, 6th International Conference, Boğaziçi Ünv., İstanbul,

531-540,

Bazant, Z. P., and Planas, J. (1998). "Fracture and size effect in concrete and other quasibrittle materials", CRC Press, Boston, 135-155,

Aydın, H. (2010). "Farklı Dayanımlı Silindir ve Küp Beton Numulerde Boyut Etkisinin İncelenmesi”. Y. Lisans Tezi.Fen Bilimleri Enstitüsü, OMÜ, Samsun, Turkey

TS500, (2000). "Betonarme yapıların tasarım ve yapım kuralları", Türk Standartları Enstitüsü, Ankara,

Bazant, Z. P., and Sun, H. H., (1987). "Size effect of diagonal shear failure; effect of aggregate size and stirrups.", ACI Materials Journal, 84(4): 259-272, 1987.

Koç V., (2007).” Beton boyut etkisi ve kırılma parametrelerinin tespiti”, BAÜ FBE Dergisi, Cilt:9, Sayı:2,150-166, Aralık

Doğangün, A. (2002). Betonarme Yapıların Hesap ve Tasarımı. Birsen Kitabevi, 94-95s, İstanbul.

Şanal, İ. (2018). "Beton Basınç Dayanım Testlerinde Küçük Ebatlı Küp Beton Numunelerin Yaygın Kullanımı İçin ŞekilBoyut Etkisinin Detaylı İncelenmesi”, Dokuz Eylül 
Üniversitesi-Mühendislik Fakültesi Fen ve Mühendislik Dergisi Cilt 20, Sayı 58, Ocak,

Hillerborg, A. (1983). Analysis of one single crack, In G-18, 223 249.

ACI Report Committee 446, (1992). "Fracture mechanics of concrete: concepts, models and determination of material properties", In Fracture Mechanics of Concrete Structures, Z.P. Bazant, Elsevier Applied Science, London,1-140

Shah, S. P., Swartz, S. E., Ouyang, C., (1995). "Fracture mechanics of concrete: applications of fracture mechanics to concrete, rock, and other quasibrittle materials", John Wiley \& Sons, Inc., NewYork, 1-35

Van Mier, J.G.M., (1997). "Fracture processes of concrete, assessment of material parameters for fracture models", $C R C$ Press, London, 1-78.

Erdoğan, F. (2000). "Fracture mechanics", International Journal of Solids Structures, 37: 171-183

Hawkins, N. M., (1984). "The role for fracture mechanics in conventional reinforced concrete desing", NATO workshop of Fract. Mech., Northwestern Univ., Evaston III, 115-168.

Carpinteri, A., (1988). "Decrease of apparent tensile and bending strength with specimen size: two different explanations based on fracture mechanics",

Carpinteri, A., Chiaia, B., Ferro, G., (1994). "Multifractal scaling law for the nominal strength variation of concrete structures in size effect in concrete structures", E\&FN Spon, London, 193-206

Tuhta, S., Günday, F., Aydin, H., (2020).”Example For Nonlinear System Identification Of Model Masonry Retaining Wall With Hammerstein-Wiener Models", Proceeding of A Multidisciplinary International Scientific Conference on Science, Technology, Education and Humanities Hosted from Ukraine, www.econferenceglobe.com,November 30th,

Tuhta S., Günday F. (2020). "Dynamic Parameters Determination of Concrete Terrace Wall with System Identification Using ANN", JournalNX, 9 / 2020

Koç, V., \& Tuhta, S. (2012). “Asma Katlı Kat Çıkmalı ve Asmolen Döşemeli Yapıların Depremsel Davranışı”. Presented at the "Samsun İlinin Deprem Riski ve Alınabilecek Önlemler Sempozyumu".

Koç, V., \& Tuhta, S. (2012). "Depremler Sonrası Zemin Katlarda Görülen Çökmelerin İncelenmesi”. Presented at the Samsun İlinin Deprem Riski ve Alınabilecek Önlemler Sempozyumu.

Tuhta, S., Günday, F., Aydın, H., \& Pehlivan, N. Ç. (2019). "Investigation of CFRP Retrofitting Effect on Masonry Dome on Period and Frequency Using Finite Element Method". Presented at the International Disaster and Resilience Congress (idRc 2019), Eskişehir.

Tuhta, S., Günday, F., Aydın, H., \& Pehlivan, N. Ç. (2019). "Investigation of CFRP Retrofitting Effect on Masonry Dome on Stress Using Finite Element Method". Presented at the International Disaster and Resilience Congress (idRc 2019), Eskişehir.

Akkaya, Y., Bayramov, F., Taşdemir, M., (2003). "Betonun Kırılma Mekaniği; Tasarımda Kullanılan Mekanik Özellikler ile Kırılma Parametreleri arasındaki Bağıntılar”. TMHTürkiye Mühendislik Haberleri,Sayı :426-2003/4

Koç, V., \& Birinci, F. (2013). Lifli Beton Boyut Etkisi Tokluk ve Kurılma Enerjisi. International Journal of Technological Science, 4(3), 24-40.

Neville A. M., (1956) The influence of size of concrete test cubes on mean strength and standard deviation Magazine of Concrete Research (8) 101-110.
Sabins G M 1979 MIRZA S M. Size Effects in Model Concrete Journal of the Structural Division 105 (ST6) 1007-1020

Yang C Q and Wu Z., (1997) Study on strength dimension effect and deformation characteristics of full-grade concrete Journal of Dalian University of Technology 37 (suppl. 1) 129-134.

Chen W, Peng G and Zhou H Q. (2014). Stress-strain analysis of uniaxial tests of concrete of different sizes under different strain rates Hydropower Energy Science 32(03) 134-137.

Che, Y., Ban, S. L., Cui, J. Y., Chen, G., \& Song, Y. P. (2010). Effect of Specimen Shape and size on Compressive Strength of Concrete. Advanced Materials Research, 163-167, 13751379. https://doi.org/10.4028/www.scientific.net/amr.163167.1375

Weibull W., (1939). Phenomenon of Rupturein Solids Proc. Royal Swdeish. Inst. Of Engineering Research (153) 1-55

Harrison Frederick Gonnerman ,1925, Effect of size and Shape of Test Specimen on Compressive Strength of Concrete, Bulletin 16, Structural materials research laboratory, Lewis institute, Structural materials research laboratory, Virginia Üniversitesi Chicago

Jin-Keun Kim., (1990). Size effect in concrete specimens with dissimilar initial cracks, Magazine of Concrete ResearchISSN 0024-9831 | E-ISSN 1751-763X ,Volume 42 Issue 153, December 1990, pp. 233-238 